\title{
Corrigendum
}

\section{Corrigendum to “The Precompression Processing of LMS Algorithm in Noise Elimination"}

\author{
Pengfei Lin $\mathbb{D}^{1},{ }^{1}$ Ning Zhang $\left(\mathbb{D},{ }^{1}\right.$ and Xingya $W u^{2}$ \\ ${ }^{1}$ College of Weaponry Engineering, Naval University of Engineering, Wuhan 430033, China \\ ${ }^{2} 91278$ Unit, Lvshunkou in DaLian 116000, China \\ Correspondence should be addressed to Ning Zhang; 18602710800@163.com
}

Received 24 August 2020; Accepted 25 August 2020; Published 12 September 2020

Copyright (c) 2020 Pengfei Lin et al. This is an open access article distributed under the Creative Commons Attribution License, which permits unrestricted use, distribution, and reproduction in any medium, provided the original work is properly cited.

In the article titled "The Precompression Processing of LMS Algorithm in Noise Elimination" [1], the corresponding author Professor Chunsheng Lin has been removed from the authors' list where Professor Ning Zhang would be the corresponding author. The correct authors' list is shown above.

\section{References}

[1] P. Lin, C. Lin, N. Zhang, and X. Wu, "The precompression processing of LMS algorithm in noise elimination," International Journal of Antennas and Propagation, vol. 2019, Article ID 2131040, 8 pages, 2019. 